DOI: 10.17117/na.2016.09.02.021

Поступила (Received): 01.09.2016

\title{
Ершов Л.А.
}

\section{Расчет прогиба балочной фермы, загруженной} по верхнему поясу и половине верхнего пояса в аналитической форме

\author{
Ershov L.A. \\ Calculation of the deflection of a girder loaded on the upper \\ belt and the upper half of the belt in an analytical form
}

Выведены точные формулы для прогиба фермы в зависимости от ее размеров, нагрузки и числа панелей. Задача определения усилий решена методом вырезания узлов по программе в системе Maple. Обобщение частных решений на общий случай получено методом индукции

Ключевые слова: ферма, прогиб, формула Максвелла-Мора, Maple

Ершов Леонид Александрович

Студент

Национальный исследовательский университет «МЭИ»

2. Москва, ул. Красноказарменная, 14
Derived exact formulas for the deflection of the truss depending on its size, load and number of panels. The problem of determining the forces in the rods are solved using cut nodes with the program in the system Maple. The synthesis of particular solutions to the general case is obtained by induction Key words: truss, trough, formula of Maxwell-Mohr, Maple

\section{Ershov Leonid Alexandrovich}

Student

National research university "MPEI"

Moscow, Krasnokazarmennaya st., 14

В работах [1-4] получен ряд точных аналитических решений для ферм, нагруженных либо сосредоточенной нагрузкой, либо нагрузкой по всей длине фермы. Использован метод индукции для обобщения решений на произвольное число панелей. Метод зарекомендовал себя как для вантовых [5], плоских [6-10], так и для пространственных ферм [11-17]. В [18-20] содержатся обзоры работ по этой теме для плоских ферм. Рассмотрим простую балочную ферму с двумя типами нагрузок. Усилия в стержнях в аналитической форме определяем по программе [21], написанной на языке системы компьютерной математики Maple.

Прогиб определяем по формуле Максвелла - Мора $\Delta=P \sum_{i=1}^{m-3} \frac{S_{i} S_{i} l_{i}}{E F}$, где $E F-$ жесткость стержней, $S_{i}$ - усилия в стержнях от действия нагрузки, $s_{i}$-усилия от действия единичной нагрузки в середине пролета, $l_{i}$ - длины стержней. В ферме с $n$ панелями число стержней, включая опорные, равно $m=8 n+4$. Суммирование производится только по деформируемым стержням (опоры предполагаются жесткими). 

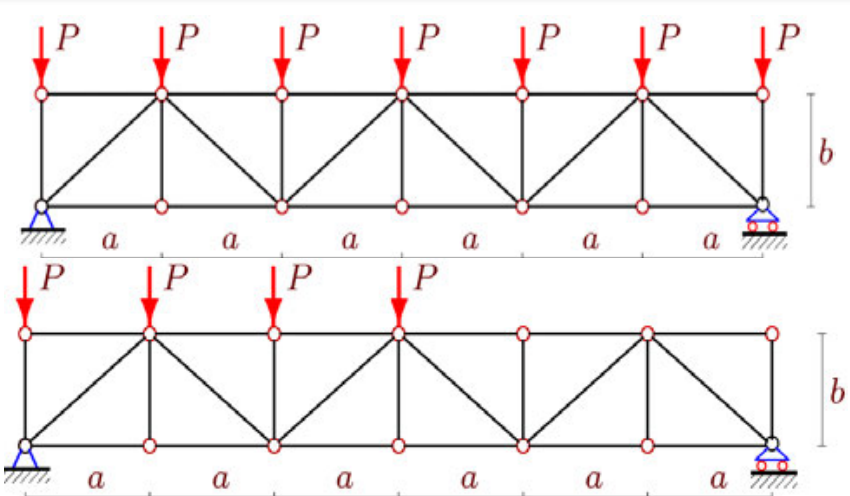

Рис. 1. Нагрузки на ферму. Случай 1 и 2. $n=3$

Из анализа серии решений для ферм с различным числом панелей были получены последовательности коэффициентов, для которых методами Maple найдены общие члены - коэффициенты искомой формулы. Получено следующее выражение для двух видов нагрузки:

$$
E F \Delta_{n}=P \frac{A_{n} a^{3}+C_{n} c^{3}}{2 b^{2}},
$$

где в случае загружения по всей длине суммарная нагрузка равна $P_{s}=P(2 n+1)$, а в случае загружения половины пролета $-P_{s}=P(n+1) ; c=\sqrt{a^{2}+b^{2}}$ $\mathrm{c}=\sqrt{\mathrm{a}^{2}+\mathrm{h}^{2}}$. Коэффициенты $A_{n}=n^{2}\left(1+5 n^{2}\right) / 6, C_{n}=n^{2}$ при нагрузке по всему пролету и $A_{n}=n(n+1)\left(5 n^{2}-n+2\right) / 12, C_{n}=n(n+1) / 2$ для половинной нагрузки получены с помощью операторов Maple rgf_findrecur и rsolve [21]. Сравнительная зависимость прогиба, отнесенного к $E F / P_{s}$, от числа панелей при $L=a n=100$ м дана на рисунке 2 .

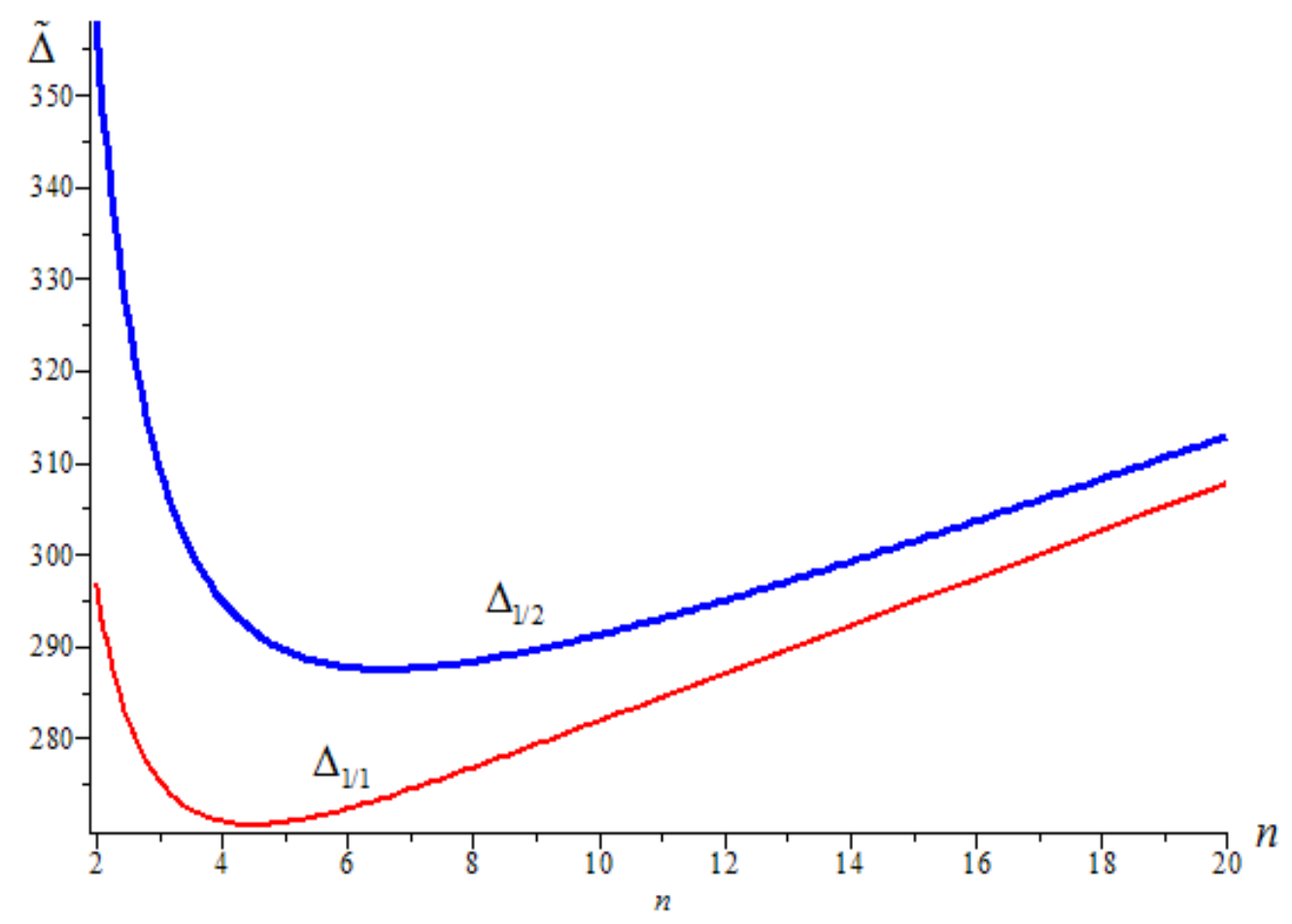

Рис. 2. Зависимость прогиба от числа панелей, $L=100 \mathrm{M}, b=10 \mathrm{M}$ 
В обеих зависимостях явно видны экстремумы - оптимальное число панелей при заданных L и b. В случае загрузки половины пролета $\left(\Delta_{1 / 2}\right)$ относительный прогиб больше, абсолютное же значение приблизительно в два раза меньше.

\section{Список используемых источников:}

1. Кирсанов М.Н. Аналитический расчет решетчатой фермы //Моделирование и механика конструкций. 2015. № 2 (2). С. 5.

2. Кирсанов М.Н. Формулы для расчета плоской балочной фермы с произвольным числом панелей//Строительная механика и конструкции. 2016. Т. 1. № 12. С. 19-24.

3. Кирсанов М.Н. Аналитический расчет балочной фермы со сложной решеткой// Строительная механика и расчет сооружений. 2015. № 3 (260). C. 7-12.

4. Kirsanov M.N. Analytical calculation, marginal and comparative analysis of a flat girder// Scientific Herald of the Voronezh State University of Architecture and Civil Engineering. Construction and Architecture. 2016.

№ 1 (29). C. 84-105.

5. Кирсанов М.Н. Статический расчет вантовой системы//Известия Московского государственного технического университета МАМИ. 2013. Т. 1. № 3. С. 89-93.

6. Dong X., Kirsanov M.N. The dependence of the deflection of the truss from the position of the load for an arbitrary number of panels//Вестник научных конференций. 2016. № 1-4 (5). C. 6-7.

7. Jiang H., Kirsanov M.N. An analytical expression for the influence line of the truss//Вестник научных конференций. 2016. № 1-5 (5). C. 10-11.

8. Al-Shahrabi A.M., Kirsanov M.N. Line of influence of the deflection for cantilever truss//Вестник научных конференций. 2016. № 2-1 (6). С. 6-7.

9. Кирсанов М.Н. Генетический алгоритм оптимизации стержневых систем // Строительная механика и расчет сооружений. 2010. № 2. С. 60-63.

10. Кирсанов М.Н. Аналитический расчет многорешетчатой фермы // Строительная механика и расчет сооружений. 2014. № 6 (257). С. 2-6.

11. Кирсанов М.Н. Статический расчет и анализ пространственной стержневой

системы//Инженерно-строительный журнал. 2011. № 6. С. 28-34.

12. Кирсанов М.Н. Аналитический расчет пространственной стержневой регулярной структуры $с$ плоской гранью//Строительная механика и расчет сооружений. 2015. № 2 (259). С. 2-6.

13. Кирсанов М.Н. Анализ прогиба фермы прямоугольного пространственного покрытия //

Инженерно-строительный журнал. 2015. № 1 (53). С. 32-38.

14. Кирсанов М.Н. Аналитический расчет пространственной стержневой системы // Строительная механика инженерных конструкций и сооружений. 2012. № 1. С. 49-53.

15. Кирсанов М.Н. Расчет пространственной стержневой системы, допускающей мгновенную изменяемость // Строительная механика и расчет сооружений. 2012. № 3. C. 48-51.

16. Кирсанов М.Н. Напряженное состояние и деформации прямоугольного пространственного стержневого покрытия // Научный вестник Воронежского государственного архитектурностроительного университета. Строительство и архитектура. 2016. № 1 (41). С. 93-100.

17. Леонов П.Г., Кирсанов М.Н. Аналитический расчет и анализ пространственной стержневой конструкции в системе Maple// В сборнике: Информатизация инженерного образования ИНФоРИНО2014 Труды международной научно-методической конференции. 2014. С. 239-242.

18. Тиньков Д.В. Анализ точных решений прогиба регулярных шарнирно-стержневых конструкций// Строительная механика инженерных конструкций и сооружений. 2015. №6. С. 21-28.

19. Тиньков Д.В. Сравнительный анализ аналитических решений задачи о прогибе ферменных конструкций // Инженерно-строительный журнал. 2015. №5(57). С. 66-73.

20. Кийко Л.К. Аналитическая оценка прогиба арочной фермы под действием ветровой нагрузки // Научный вестник. 2016. № 1 (7). С. 247-254.

21. Кирсанов М. H. Maple и Maplet. Решения задач механики. СПб.: Изд-во Лань, 2012. 512 c.

(C) 2016, Ершов Л.А.

Расчет прогиба балочной фермы, загруженной по верхнему поясу и половине верхнего пояса в аналитической форме
(C) 2016, Ershov L.A.

Calculation of the deflection of a girder loaded on the upper belt and the upper half of the belt in an analytical form 